\title{
Mechanisms by which stress can lead to coronary heart disease
}

\author{
James P. Henry \\ Department of Psychiatry, School of Medicine, Loma Linda University, Loma Linda, CA 92350, USA.
}

\begin{abstract}
Summary: Much stress is of psychological origin and due to emotional arousal. The mechanisms by which anger, helplessness, or a sense of control and serenity exert their various neuroendocrine effects are discussed. Primacy is given to three systems; to the catecholamines, to testosterone and to cortisol. Evidence that they interact to accelerate the arteriosclerotic process is cited. The protective aspects of intimacy are discussed together with evidence that certain personality types promote it in the marital situation while others do not. It is suggested that the post-traumatic stress syndrome may relate to the coronary-prone personality for it involves an alexithymic disturbance of the emotional competence required for successful intimacy.
\end{abstract}

In an updating of Selye's concept of stress, psychobiologist Levine points out that the stimuli often are psychological and that complex multiple response systems are involved. Indeed, various psychosocial factors trigger three different hormonal systems (Levine, 1985). The first of these is the adrenocortical system. It responds primarily to situations which he describes as leading to a high degree of 'uncertainty'. To behavioural biologist Miller this uncertainty implies a loss of control as is demonstrated by the elegant experiments of his associate Weiss using yoked rats. Each rat had an electrode on its tail and received the same shocks as the other but only one had active control and could prevent punishment by pressing a lever in response to a warning light. This animal showed less emotional arousal and fewer pathophysiological changes than the one forced to be passive (Miller, 1980). Thus one of the factors triggering the sense of uncertainty is a situation that is aversive and defies efforts to establish control. Another is a novel situation which arouses the anxious perception that control might be lost.

A second group of hormones is regulated by the gonadotrophic system which is responsible for the secretion of androgens and oestrogen and progesterone. Both suppression and elevation of these hormones appears to be determined by the extent to which the organism feels secure and in the case of androgens the sense of 'potency', i.e. the dominance and control the individual has over a challenging situation. In a current extensive review of available human data (in preparation), sociologist Kemper has concluded that in a whole variety of situations testosterone is increased when this sense of control is activated. Certainly a rise in testosterone can enhance the libido and

Correspondence: J.P. Henry, M.D., Ph.D. attractiveness of the individual to potential sexual partners. In addition, an increase occurs after any competition for status such as the winning of a hard fought tennis match - the situation studied by Mazur \& Lamb (1980).

Finally, to Levine the familiar catecholamine fightflight, sympathetic adrenomedullary axis is crucially involved in the response to situations that require attention or vigilance (Levine, 1985). When the situation involves an aggressive, directed attack then noradrenaline is involved; and in situations where uncertainty and anxiety is building up adrenaline and noradrenaline are involved (Henry \& Stephens, 1977).

Figure 1 presents these same concepts in a form which relates the patterns of neuroendocrine response to emotions. We see Levine's three hormonal systems as the expression of differing instincts. The pituitary/ adrenal mechanism is strongly aroused in a psychosocial context when the attachment behaviour that is necessary for the bonding that holds the social system together is threatened. Human evolution has led to the development of adult male-female attachment bonds that are as permanent as the older mammalian attachments bonding mother to young. This male-female bonding ensured the unique cohesion of primitive social groups. Other primates leave the females and young to seek food for themselves. The hunter-gatherer pattern of living involves an extended family group (Henry \& Stephens, 1977). During the one to two million years of man's evolution, such small group living was the pattern. Vilensky suggests that the period was long enough to permit the evolution of special emotional patterns that tend to stabilize the social group (Vilensky et al., 1982).

This instinct for attachment leads to the formation of a cohesive family group incorporating several adults of both sexes. It is characteristic even of 


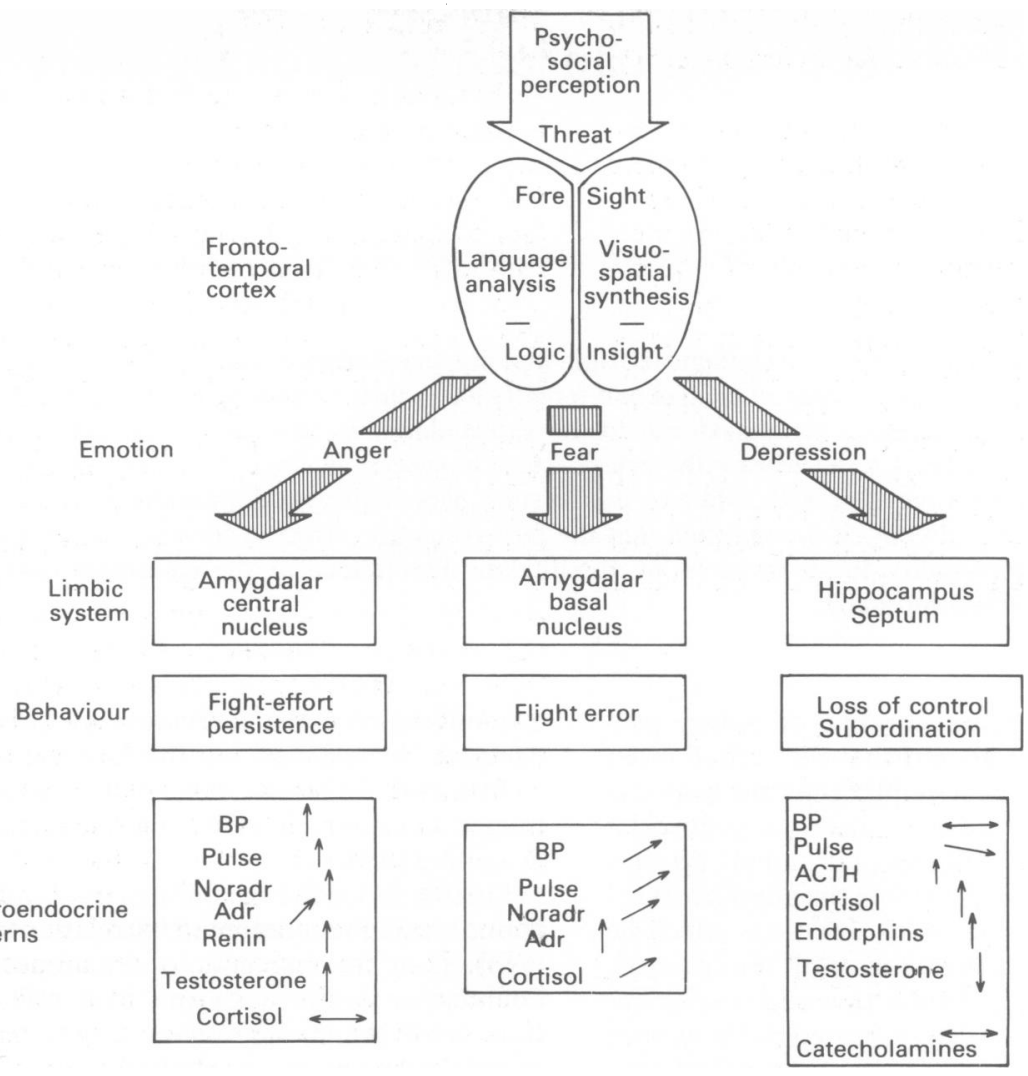

Figure 1 Psychosocial stimulation by the external environment can result in a perception of challenge by the sociocultural analysers of the frontotemporal cortices. Ventral frontoamygdalar pathways arouse the central nucleus if anger is involved; the basal nucleus if fear is involved; and dorsalfrontal activity pathways arouse the hippocampus and septum if depression is involved. In contrast to the fight-flight response of the amygdala, the hippocampus involves a depressive response characterized by helplessness and loss of control. The associated neuroendocrine patterns differentiate between three responses: noradrenaline (anger), adrenaline (fear) and cortisol (depression). $\quad \mathbf{B P}=$ blood pressure; Noradr $=$ noradrenaline; $\mathbf{A d r}=$ adrenaline; $\uparrow=$ sharp increase; $\nearrow=$ moderate increase; $\downarrow=$ decrease; $\leftrightarrow=$ no change.

primitive human groups that they are made up of experts with different skills, e.g. weapons fabrication, hunting, fishing, needlecraft, etc. A group big enough to permit such specialization means that the expert controls while the others follow. Then with turnabout the follower takes over as the expert in his area. The hormones support these changes in status. The ancient positive response of the human gonadotrophic system to the achievement of control is associated with an increase of the plasma testosterone level both in male and probably female, the source in the female being the adrenal cortex. Loss of status due to group perceived incompetence and performance failure results in decrease of the hormone (Rose et al., 1975; Mazur \& Lamb, 1980). The accompanying behaviour involves a loss of persistence and drive. This is a mechanism for giving temporary control to the one with the appropriate competence for the particular task facing the group at the time.

The master instinct of territoriality is fuelled by the sympathetic adrenomedullary-catecholamine response. This is aroused when there is need for attention and vigilant preparedness to act in defense of resources (Henry, 1982). It has been shown in recent work with conscious animals and in studies of the neurophysiology of the adrenal medulla that the adrenaline and noradrenaline response capabilities can be separated. Each responds to its own particular behaviour pattern: noradrenaline with the aggressive fight response and typical elevation of blood pressure 
and vasoconstriction; adrenaline with the classical flight with vasodilatation and a tachycardia (Henry, 1985).

As Levine (1985) makes clear in his review, in the extreme state of response to a strong challenge all these systems are activated at the same time. There is evidence that such multiple hormonal shifts provide a milieu fostering the disturbed metabolism of atherosclerosis. The extraordinary long-term studies of Kaplan, with competing monkeys which can never achieve social control, support the thesis that the combination of chronic emotional arousal with its disturbance of both the sympathetic adrenomedullary and the pituitary-adrenocortical system together with dietary hyperlipidaemia is far more effective in inducing atherosclerosis than when lipid intake is increased in a relaxed and secure animal (Manuk et al., 1983).

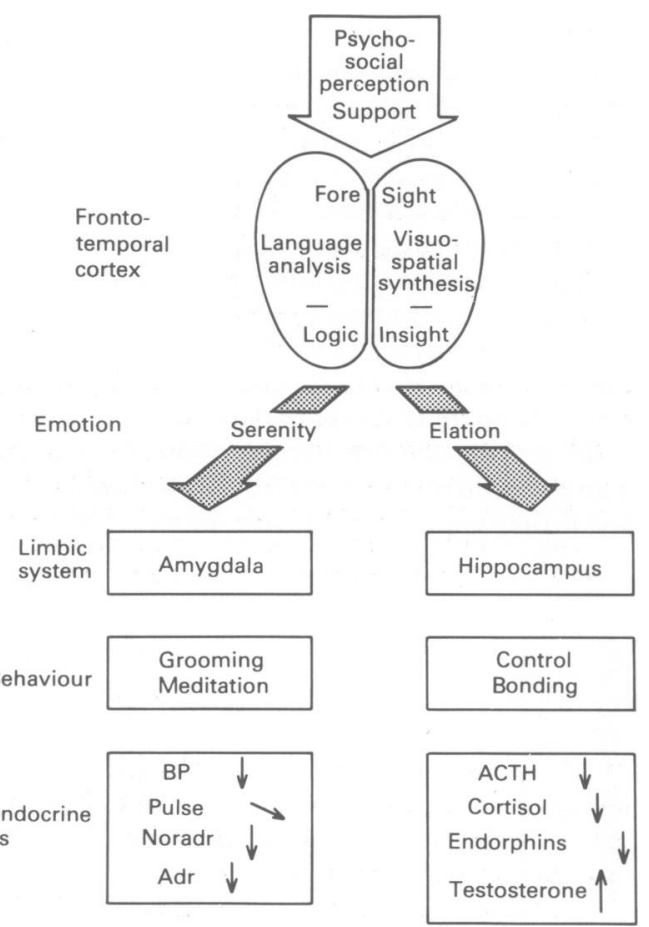

Figure 2 Amygdalar and hippocampal responses to psychosocial perception of support, solidarity and bonding lead to a feeling of relaxation: the amygdala is involved. Grooming behaviour and decreased arousal of the sympathetic adrenomedullary system lead to a fall in blood pressure, catecholamines, and renin. With the elation of limerance and bonding, there is hippocampal arousal, and cortisol and endorphins decrease. Testosterone may increase (For abbreviations see legend to Figure 1).

\section{The protection of intimacy}

As Figure 2 indicates, a relaxed and secure state which is accompanied by the emotions of serenity and elation will produce hormonal changes the opposite of anger, fear and depression. Intimacy or the capacity to love and to maintain a dyadic relationship is associated with mental health and with serene and elated states. Thomas et al. (1985) have shown that those who enjoy good social support systems, as measured by having satisfying intimate confidant relationships, had lower levels of serum cholesterol, uric acid and higher lymphocyte counts and mitogen responses than persons lacking such support. It may be relevant that the successful maintenance of marital intimacy is not part of the coronary Type A pattern of behaviour. Indeed, as Rubin (1983) points out most husbands are not cited by their wives as intimate confidantes. This despite the fact that men in general cite their wives as their most important confidantes. Thus the greater vulnerability of men to coronary heart disease may be connected with some failure in the sphere of intimacy.

Waring describes marital intimacy as a capacity to express affection, feelings of closeness, compatibility, i.e. ability to work and play together with a sharing of the same value systems; ability to resolve differences of opinion, and commitment to the relationship (Waring, 1984). The communication of sexual needs and their fulfilment was also a factor but it was not critical. Ganellen \& Blaney (1984) have argued recently that a critical factor behind Kobasa's concept of the need for 'hardiness' in order to survive stressful challenge (Kobasa et al., 1983), is the capacity to make intimate friends, i.e. of having a confidante. The greater capacity of women to form social attachments and the greater importance they place on bonding behaviour is described by Gilligan in her now classic In a Different Voice (1982). As Kemper points out, the facts of inequalities between two people are less important to a woman perhaps because of a different early experience. As an infant she perceives herself to be female, i.e. the same sort as her mother and therefore closely attached. This occurs despite their mutual recognition of the gross disparity between their capacities and this may be a factor in acquiring skill in forming intimate bonds with others.

\section{Social status of the marital dyads and heart disease}

Recently there has been a flurry of papers on the relationship between wives' social and psychological status and their husband's coronary heart disease. Carmelli et al. (1985) note that Type A men married to women with thirteen or more years of schooling have an increased 'odds ratio' of 3.6 for coronary disease as compared to 0.4 in Type B men. Eaker et al. (1983) 
found that the highest risk is Type A blue collar men married to Type B highly educated and successful wives (Figure 3). Perhaps the clue is the difference in the basic interests of men and women. Frankenhaeuser (1983) has shown that women faced with a challenging physical or intellectual task are less aroused and challenged than men facing the same challenge and put out less catecholamines in the urine. At first it was thought that women were less responsive to stress than men but if faced with a difficult problem in social relationships then the shoe is on the other foot and they become strongly aroused. This different orientation of men and women may bedevil the marriage of a blue collar Type A man to the Type B successful, educated woman. Lacking a sophisticated sense of intimacy and the associated skills the man is oriented towards power, control and abstract concepts of justice. Perhaps, if she is Type B, relaxed and not controlling, the woman is not able to train him in the art of human relationships. But a Type A, ambitious



Figure 3 Ten-year incidence of coronary heart disease (CHD) among men aged 45-64 years by educational level of wives. Framingham Heart Study (Eaker et al., 1983). woman will be more easily able to persuade her own sort of their importance. She will be able to convince him to accept her lead in social graces, birthdays and celebrations, even if he is hostile and mistrustful of the rest of the world (Williams et al., 1980). Medalie \& Goldbourt's (1976) data show men who cannot do this and who perceive their wives as nonsupportive are at twice the risk of developing coronary disease (Figure 4).

\section{Social support and low cortisol levels}

There is evidence that in mammals, buffering by groups or by individuals of the same species will decrease the response to stress (Figure 5). Rats tested in groups show less behavioural responsiveness to a fear stimulus than rats tested individually (Taylor, 1981). Stanton et al. (1985), working in Levine's laboratory, have recently shown that monkeys trained to fear a light because it signals a shock, evince no fear when in a familiar group whose members are not so trained and ignore the light: the subjects' cortisol remains normal. Dyadic relations with others of the same sex were also protective but less so (Figure 5). Von Holst (in press) has shown that even in captivity some male and female tree shrews will form harmonious breeding pairs. Such attached pairs show much intimate behaviour including prolonged mutual tongue licking and sleeping together. The pulse rate of the males in these dyads is significantly lower $(20 \%)$ than controls (Von Holst, in press). The above animal studies are compatible with the idea that the potentially deleterious neuroendocrine changes occurring in a man or a woman threatened by life's challenges will be less if they enjoy a supportive, intimate relationship.

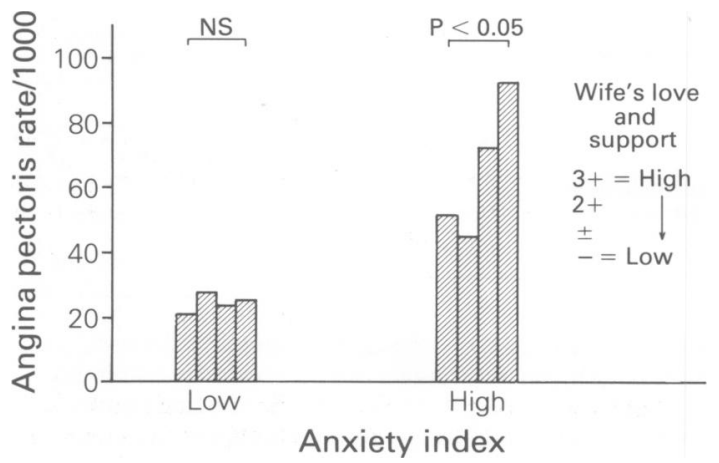

Figure 4 The incidence of angina in Israeli civil servants having a good relationship with their spouses is contrasted with the incidence in those who perceive their relationship as non-supportive. Anxiety is an important cofactor (Medalie \& Goldbourt, 1976). 


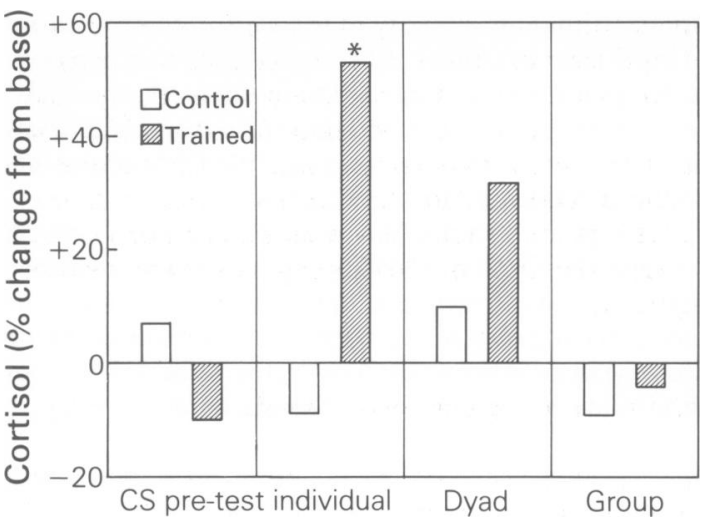

Figure 5 Cortisol responses in monkeys to 10 nonreinforced, light bulb conditioned stimulus presentations. These were made in the home cage before training to associate the stimuli with electric shock (CS pre-test) and after training (Individual, Dyad and Group). Thus the effects of housing with various untrained conspecifics were compared with the solitary condition; this was the state in which the CS pre-test data was obtained. (* $=$ differs from control and $0 \%$ base line $P<0.05$ ) (Taylor, 1981).

\section{Alexithymia: blindness to emotion}

Recently evidence has been presented that psychic trauma, either in the early stages of development as an infant or even in later life as in the case of torture, can lead to permanent and demonstrable damage in the central nervous system (Henry, 1986, Kellner et al., 1983). The condition of alexithymia or failure to perceive emotion (Taylor, 1986), which, according to Defourny et al. (1976/77) characterizes the coronaryprone personality, may have some of its roots in the attempt to adjust to an anxious mistrustful perception of the demands of society (Shipko et al., 1983). As a consequence of early or late trauma, emotional responses become permanently disturbed in the attempt to maintain control (Krystal, 1978). There is evidence that the mechanism may involve damage to hippocampal brain cells due to high levels of adrenal cortical hormones (Sapolsky et al., 1984). Damaged, alexithymic, coronary-prone persons may not have proper access to those instinctual patterns which are heavily involved with the right hemisphere (Sacheim et al., 1982). Yet access to the right temporal system with its subtlties of emotionality is needed as a balance to the more logical, problem-orientated left (Ross, 1984). Antonovsky's (1979) 'coherence', Kobasa's (Kobasa et al., 1983) 'hardiness' and Jung's 'individuation' (Stevens, 1981), may have much in common and imply



Afferents from stomach colon bladder atria

Figure 6 A schematic drawing illustrating a new view of NE-LC function. As indicated on the lower left, NE-LC neurons are excited by sensory stimuli or spontaneously occurring alertness. Conversely, the lower right section of this drawing illustrates behavioural states which are associated with suppressed NE-LC activity. The hypothesis states that enhanced activity traversing the elaborate efferent projections of the NE-LC system (as a result of enhanced external signals) biases the orientation of brain and behaviour activities so as to deal preferentially with external events that arouse the organism, challenging the perception of control. Conversely, diminished NE-LC activity would allow internally oriented, more instinctual brain and behavioural programs to be expressed (Shipko et al., 1983). 
integrated left-right activity. The secret of the competence of such people may be free communication between two healthy, undamaged hemispheres. The mechanism switching between the two systems is now believed be located deep in the brainstem in the tiny locus coeruleus (Antonovsky, 1979) (Figure 6). The existence of a challenging situation demanding great and sustained effort to achieve control, leads to chronic arousal of the left hemisphere. The individual who even when he goes home cannot relax and share intimate emotions with a confidante because he is confined to this emergency action mode is at risk of being left alone to cope. As Aston-Jones et al. (1984)

\section{References}

ANTONOVSKY, A. (1979). In Health, Stress and Coping. New Perspectives on Mental and Physical Well-being. JosseyBass. San Francisco

ASTON-JONES, G., FOOTE, S.L. \& BLOOM, F.E. (1984). Anatomy and physiology of locus coeruleus neurons: functional implications. In Frontiers of Clinical Neuroscience, Vol. 2 Norepinephrine, Ziegler, M.G. and Lake, C.R. (eds). Williams \& Williams. Baltimore

CARMELLI, D., SWAN, G.E. \& ROSENMAN, R.H. (1985). The relationship between wives' social and psychologic status and their husbands' coronary heart disease. A case-control family study from the Western Collaborative Group Study. American Journal of Epidemiology, 122, 90.

DEFOURNY, M., HUBIN, P. \& LUMINET, D. (1976/77). Alexithymia, "pensee operatoire" and predisposition to coronopathy. Psychotherapeutics and Psychosomatics, 27, 106.

EAKER, E.D., HAYNES, S.B. \& FEINLEIB, M. (1983). Spouse behaviour and coronary heart disease in men: prospective results from the Framingham study 11. American Journal of Epidemiology, 118, 23.

FRANKENHAEUSER, M. (1983). The sympathetic-adrenal and pituitary-adrenal response to challenge: comparison between the sexes. In Biobehavioral Bases of Coronary Heart Disease, Dembroski, T.M. and Schmidt, T.H. (eds). Karger: Basel, Munchen, Paris, London, New York, Tokyo, Sydney.

GANELLEN, R.J. \& BLANEY, P.H. (1984). Hardiness and social support as moderators of the effects of life stress. Journal of Personality and Social Psychology, 47, 156.

GILlIGAN, C. (1982). In a Different Voice. Psychological Theory and Women's Development. Harvard University Press: Cambridge, Massachusetts and London, England.

HENRY, J.P. \& STEPHENS, P.M. (1977). In Stress, Health and the Social Environment. A Sociobiologic Approach to Medicine, Schaefer, K.E. (ed.) Springer-Verlag: New York.

HENRY, J.P. (1982). The relations of social to biological processes in disease. Social Science and Medicine, 16, 369.

HENRY, J.P. (1985). Neuroendocrine patterns of emotional response. In Emotion, Theory, Research and Experience, Plutchik, R. and Kellerman, H. (eds), Vol.3, p. 36. Academic Press: New York.

HENRY, J.P. (1986). Relation of psychosocial factors to the put it: 'Enhanced activity in the elaborate projections of the locus bias the orientation of brain and behavior to external events and so to control. Conversely, diminished noradrenaline locus activity would allow internally-orientated, more instinctual brain and behavioral programs to be expressed.'

Perhaps in alexithymia and the related Type A personality (Defourny, 1976/77) there is a breakdown in the capacity to switch at appropriate times from the mode of control and to consult the direction-giving archetypes or inborn patterns that we inherit from our thousands of millenia of hunter-gatherer ancestry.

epidemiology of senile dementia. In The Dementias: Policy and Management. Gilhooly, M.F.M., Zarit, S.H. and Birren, J.E. (eds). Prentice-Hall, Inc.: Englewood Cliffs, New Jersey.

KELLNER, C.H., ROY-BYRNE, P.P., RUBINOW, D.R., GOLD, P.W. \& POST, R.M. (1983). Cerebral atrophy in torture victims. New England Journal of Medicine, 308, 90.

KOBASA, S.C., MADDI, S.R. \& ZOLA, M.A. (1983). Type A and hardiness. Journal of Behavioral Medicine, 6, 41.

KRYSTAL, H. (1978). Trauma and effects. The Psychoanalytic Study of the Child, 33, 81.

LEVINE, S., (1985). A definition of stress? In Animal Stress Moberg, G.P. (ed). p. 51. American Physiological Societ Bethesda, Maryland.

MANUCK, S.B., KAPLAN, J.R. \& CLARKSON, T.B. (1983) Social instability and coronary artery atherosclerosis in Cynomolgus monkeys. Neuroscience and Biobehavioral Reviews, 7, 485.

MAZUR, A. \& LAMB, T.A. (1980). Testosterone, status and mood in human males. Hormones and Behavior, 14, 236.

MEDALIE, J.H. \& GOLDBOURT, U. (1976). Angina pectoris among 10,000 men. II. Psychosocial and other risk factors as evidenced by a multivariate analysis of a five-year incidence study. American Journal of Medicine, 60, 910.

MILLER, N.E. (1980). Effects of learning on physical symptoms produced by psychological stress. In Selye's Guide to Stress Research, Selye, H. (ed.) p. 131. Van NostrandReinhold: New York.

ROSE, R.M., HERNSTEIN, I.S. \& GORDON, T.P. (1975). Consequences of social conflict on plasma testosterone levels in Rhesus monkeys. Psychosomatic Medicine, 37, 50.

ROSS, E.D. (1984). Right hemisphere's role in language, affective behavior and emotion. Trends in Neurosciences, 7 , 342.

RUBIN, L. (1983). In Intimate Strangers. Harper-Row: New York

SACHEIM, H., GREENBERG, M.S., WEIMAN, A.L., GUR, R.C., HUNGERBUHLER, J.P. \& GESCHWIND, N. (1982). Hemispheric asymmetry in the expression of positive and negative emotions. Archives of Neurology, 39, 210.

SAPOLSKY, R.M., DREY, L.C. \& McEWEN, B.S. (1984). Stress down-regulates corticosterone receptors in a site-specific manner in the brain. Endocrinology, 114, 287.

SHIPKO, S., WILLIAM, A. \& NICHOLAS, N. (1983). Towards a 
teleological model of alexithymia and post-traumatic stress disorder. Psychotherapeutics and Psychosomatics, 39, 122.

STANTON, M.E., PATTERSON, J.M. \& LEVINE, S. (1985). Social influences on conditioned cortisol secretion in the squirrel monkey. Psychoneuroendocrinology, 10(2), 125.

STEVENS, A. (1981). In Archetypes. Morrow: New York.

TAYLOR, G.J. (1986). Alexithymia: concept, measurement and implications for treatment. American Journal of Psychiatry, 141, 725.

TAYLOR, G.T. (1981). Fear and affiliation in domesticated male rats. Journal of Comparative Physiological Psychology, 95, 685.

THOMAS, P.D., GOODWIN, J.M. \& GOODWIN, J.S. (1985). Effect of social support on stress related changes in cholesterol level, uric acid level and immune function in an elderly sample. American Journal of Psychiatry, 142, 735.

VILENSKY, J.A., VAN HOESEN, G.W. \& DAMASIO, A.R. (1982). The limbic system in human evolution. Journal of Human Evolution, 11, 447.

VON HOLST, D. (in press). Vegetative and somatic components of tree shrew's behavior. Journal of the Autonomic Nervous System.

WARING, E.M. (1984). The measurement of marital intimacy. Journal of Marital and Family Therapy, 10, 185.

WILLIAMS, K.B. JR., HANMEY, T.L., LEE, K.L., KONG, Y.H., BLUMENTHAL, J.A. \& SHALEN, R.E. (1980). Type A behavior, hostility and coronary atherosclerosis. Psychosomatic Medicine, 42, 539. 